\title{
Psychometric Properties of the Italian Version of the Smartphone Application-Based Addiction Scale (SABAS)
}

\author{
Paolo Soraci $^{1} \cdot$ Ambra Ferrari $^{2} \cdot$ Urso Antonino $^{3} \cdot$ Mark D. Griffiths $^{4}$
}

Published online: 23 January 2020

(C) The Author(s) 2020

\begin{abstract}
The aim of the present study was to test the psychometric properties of the Italian version of the Smartphone Application-Based Addiction Scale (SABAS; Csibi et al., International Journal of Mental Health and Addiction, 16, 393-403, 2018), a short and easy to use six-item tool for screening the risk of addiction to smartphone-based applications. A further goal was to explore the impact on smartphone addiction of several variables related to smartphone use habits, perceived quality of life, and sociability measures. The data were collected online from 205 Italian-speaking volunteers (128 males and 77 females aged 18 to 99 years). The psychometric instruments included in the study were the SABAS and the Nomophobia Questionnaire (NMP-Q). Psychometric testing showed that the six items included in the SABAS comprised a unidimensional factor with good reliability (Cronbach's alpha $=.890$ ). Therefore, the SABAS appears to be a reliable instrument to assess the risk of addiction to smartphone apps. Moreover, longer daily time spent using the smartphone was found to be positively correlated with the total SABAS and NMP-Q scores, while perceived quality of life and self-reported sociability were found to be negatively correlated with such scores.
\end{abstract}

Keywords Mobile phone addiction · Smartphone addiction · Nomophobia $\cdot$ Social media addiction $\cdot$ Smartphone application addiction $\cdot$ Italian $\cdot$ Questionnaire

Mark D. Griffiths

mark.griffiths@ntu.ac.uk

Associazione Italiana di Psicoterapia Cognitivo - Comportamentale di Gruppo, Rome, Italy

2 Dipartimento di Scienze Della Formazione "Riccardo Massa", Università degli Studi di Milano Bicocca, Milan, Italy

3 Facoltà di Scienze Sociali, Pontificia Università San Tommaso, Rome, Italy

4 International Gaming Research Unit, Psychology Department, Nottingham Trent University, Nottingham NG1 4FQ, UK 
During the past recent years, new information and communication technologies (ICTs) have become widespread and are being increasingly used in modernized cultures. Because of their frequent use and their omnipresent nature, ICTs have become an almost irreplaceable part of a highly dynamic and interconnected society. Smartphones represent the latest evolution of ICTs, and they have initiated a new age in the present culture, defined as the "mobile era." According to the Pew Research Center survey, $71 \%$ of the Italian population (where the present study was carried out) owned a smartphone in 2019 (Taylor and Silver 2019) and this figure is expected to grow over the next few years.

Although mobile devices allow users to perform a variety of tasks quickly, easily, and effectively, they can (in extreme cases) also lead to serious medical and physical problems. For instance, from a physical point of view, these problems include poor physical fitness (Guthold et al. 2020; Lepp et al. 2015; Rebold et al. 2016), sleep deprivation (van der Schuur et al. 2019), excessive exposure to radiation (Stevens and Egger 2017), "screen dermatitis" (Corazza et al. 2016), tumors (Kim et al. 2016; Heo et al. 2017), and infertility (Belyaev et al. 2015). Mobile devices can also interfere with driving safety and cause serious accidents (International Telecommunication Union 2019). In Italy, 145,815 traffic law violations involved mobile phone use while driving in 2017 (Istituto Nazionale di Statistica/Automobile Club Italia 2018).

Scholars have also reported several mental health problems among excessive mobile device users, including poor academic performance (David et al. 2015; Lepp et al. 2015) and increased risk of depression, anxiety, and stress (e.g., Elhai et al. 2017b). A systematic review of 117 studies (Elhai et al. 2017a) concluded that the severity of depression, anxiety, and stress was associated with problematic smartphone use. More specifically, among psychological disorders and syndromes strictly related to smartphone use, scholars have reported "texting addiction" (Martinotti et al. 2011) and "selfitis" (the obsessive taking of selfies [Balakrishnan and Griffiths 2018]). Several other new smartphone-based behaviors, such as "sexting" (sending and receiving sexually explicit messages [Rice et al. 2012]) and "phubbing" (ignoring individuals in social situations, engaging in mobile phones activities instead [Chotpitayasunondh and Douglas 2018]), may not represent particular risks for the users' health but these seemingly harmless behaviors, if carried out to the extreme, might also become problematic (Chotpitayasunondh and Douglas 2016; Roberts and David 2016).

Because the pervasiveness and intrusiveness of smartphones can lead to such problematic and/or compulsive use in a minority of cases, some scholars consider these habits as a behavioral dependence, and therefore a variant of technological dependence (Salehan and Negahban 2013). In fact, psychological literature describes several commonalities between maladaptive use of the internet and smartphones, including symptoms such as obsessivecompulsive behaviors (Kuss and Griffiths 2012; Kuss et al. 2014; Lopez-Fernandez 2015; Kardefelt-Winther 2014b). Other scholars consider problematic smartphone use as a specific dependence, culminating in what has been called "smartphone addiction" (Kuss and Griffiths 2017).

The reliance on mobile smartphones has also led to the rise of nomophobia (i.e., no-mobile phone phobia) describing the transitory psychological suffering related to individuals not having their smartphone at hand and/or the fear of losing it (Yildirim and Correia 2015). This led to the development of the Nomophobia Questionnaire (NMP-Q) to assess the condition (Yildirim and Correia 2015). Whereas mobile phone dependence is defined as a loss of control on phone use that interferes with other activities, nomophobia refers to a pathological fear of individuals not having their smartphone (Chóliz 2012) and there is evidence suggesting the two constructs are highly correlated (Kuss and Griffiths 2017). 
A further debate concerns whether it is the applications that individuals become addicted to (e.g., social networking, gaming, gambling), rather than to the smartphone itself (Csibi et al. 2018; Griffiths and Szabo 2014; Pontes et al. 2015). For instance, Kuss and Griffiths (2017) claimed individuals are "no more addicted to smartphones than alcoholics are addicted to bottles" (p. 8). Recent studies examining smartphone use have in fact suggested that only a small minority of the general population using smartphones in their everyday life shows symptoms suggesting an addiction (e.g., Billieux et al. 2015; Elhai et al. 2017b; LopezFernandez 2017).

Recent studies have investigated which smartphone applications are the most prevalently used and which underlying psychological comorbidities such as depression and/or anxiety may be present with excessive use of them. Among others, the habit of checking notifications can provide positive emotions and reduce negative ones (Billieux et al. 2015). However, if compulsively done in search of reassurance and/or for "fear of missing out" (FOMO), it may lead to symptoms of low self-esteem, loneliness, anxiety, increased depressive symptoms, and more generally, decreased psychological wellbeing (Jeong et al. 2016; Billieux et al. 2015; Elhai et al. 2016). This is the reason why social media addiction has a significant association with smartphone addiction (Kuss and Griffiths 2017; Banyai et al. 2017), and users who make great use of social networking and gaming are more likely to develop symptoms of dependence than those using smartphones for study and/or work purposes (Demirci et al. 2015; Jeong et al. 2016; Salehan and Negahban 2013).

Following such disputes, the terminology that currently describes the problematic use of the smartphone is inconsistent and varied, as evidenced by the interchangeable use of a variety of terms including "addictive," "excessive," "compulsive," "compensatory," and "problematic,"(e.g., Kardefelt-Winther 2014a, b; Widyanto and Griffiths 2006; Billieux et al. 2017). The lack of clarity of such terms has led to inarguably complex definitions of smartphone behavior, involving different psychological constructs such as functional impairment, lack of control, and/or dysfunctional coping (Long et al. 2016).

Consequently, smartphone addiction as a construct has led to the creation and development of many different psychometric tools intended to assess symptoms (e.g., Lin et al. 2014). One such assessment tool is the Smartphone Application-Based Addiction Scale (SABAS), developed by Csibi et al. (2018), which assesses the risk of addiction to applications accessed via smartphones (rather than an addiction to smartphones themselves). The SABAS is a short and easy to use six-item instrument that has been validated in various languages including Hungarian (Csibi et al. 2016), Persian (Lin et al. 2019), and Chinese (Yam et al. 2019). However, an Italian version has never been validated. Therefore, the purpose of the present study was to test the psychometric properties of the Italian SABAS. Three hypotheses are identified in relation to its psychometric value:

- Hypothesis 1. The SABAS will have a unidimensional factorial structure with a loading of $\geq .50$ on every item, and its main adaption indexes will be sufficient (root mean square error of approximation $[\mathrm{RMSEA}]<.08$, comparative fit index $[\mathrm{CFI}]>.80$ ).

- Hypothesis 2. The SABAS will have a medium-high internal consistency related to its six items (Cronbach's alpha $>.70$ ).

- Hypothesis 3. The SABAS will be positively correlated with a questionnaire assessing a related construct (i.e., the Nomophobia Questionnaire [NMP-Q]), and therefore theoretically associated with it $(r \geq .50)$. 


\section{Methods}

\section{Participants and Procedure}

Data were collected from 210 Italian participants aged 18 to 99 years (mean $=33.8$ years; $\mathrm{SD}=16.2$ ). Of these, five were excluded from the final sample because they did not complete all the measures. The final sample included 205 participants (128 males and 77 females). According to literature, there should be at least 10 participants for each scale item (Comrey 1988), and since the number of scale items is six, the final sample size was deemed to be acceptable. The research design was cross-sectional, and individuals were invited to participate in an online survey via Google Forms (an open-source tool for developing and distributing online questionnaires). Given the exploratory nature of the study, a convenience sampling strategy was used. The online survey link was mainly disseminated among university students, based on the notion that individuals in this age group were more likely to use and rely on their smartphone than other potential populations.

\section{Measures}

Smartphone Application-Based Addiction Scale (SABAS; Csibi et al. 2018) The SABAS is a six-item scale that assesses the risk of smartphone application-based addiction based upon the components model of addiction (Griffiths 2005). Example items include "If I cannot use or access my smartphone when I feel like, I feel sad, moody, or irritable" and "Conflicts have arisen between me and my family (or friends) because of my smartphone use." Items are rated on a six-point Likert scale from 1 (strongly disagree) to 6 (strongly agree). The scale was translated from English into Italian in the present study following the protocol described by Beaton et al. (2000). More specifically, the scale was translated by Italian psychologists into Italian, and then the Italian items were back-translated by a native Italian translator (who had never seen the scale before) and translated the items back into English. All translators compared all forward and backward translated versions to consolidate and develop an interim Italian version of the SABAS. This was then piloted on 20 participants of different ages and education levels to investigate if there could be any problems in understanding the items.

Nomophobia Questionnaire (NMP-Q; Yildirim and Correia 2015) The NMP-Q is a 20-item scale that assesses four main dimensions of nomophobia: not being able to communicate, losing connectedness, not being able to access information, and giving up convenience. Example items include "If I could not check my smartphone for a while, I would feel a desire to check it" and "If I could not use my smartphone, I would be afraid of getting stranded somewhere." Each item is rated on a seven-point Likert scale ( 1 = strongly disagree and $7=$ strongly agree). The NMP-Q was translated into Italian by Adawi et al. (2018). Cronbach's alpha in the present study was .85 and for the four subscales was $.87, .86, .84$, and .83 respectively. No problematic univariate outlier was observed while observing interquartile ranges of four factors.

Demographics The present study included some demographic questions (gender, age, educational level, relationship status), in order to highlight personal characteristics that may influence the SABAS score. 
Smartphone Use The survey also included questions concerning smartphone use responded to on a five-point Likert scale $(1=$ very little and $5=$ very $m u c h)$. Questions included frequency of daily use of smartphone applications (i.e., "How often do you use smartphone apps every day?"), the degree of perceived importance of the smartphone in the participant's life (i.e., "How important is it for you to use the smartphone in your life?"), and frequency of online purchases of smartphone apps (i.e., "How often do you buy smartphone apps online?"). Such questions were included in order to assess behaviors that may influence the SABAS score and are variables that have been associated with the problematic use of the smartphone (e.g., Jiang and Zhao 2016).

Quality of Life Measure One item related to the perceived quality of life (i.e., "How satisfied are you with your life?") answered on a Likert scale ( $1=$ very little and $5=$ very much). This item was included to examine how satisfied participants were with their life because any addiction affects the quality of life as suggested by many previous studies (e.g., Ezoe et al. 2009).

Socialization Measure One item related to the self-reported degree of sociability "offline" (i.e., "Do you consider yourself sociable?") answered on a Likert scale ( 1 = very little and $5=$ very much) and self-reported degree of sociability "online" (i.e., "How often do you establish friendship or love relationships with people you know online through chat, forums, social networks or video games?") answered on a Likert scale ( $1=$ never and $5=$ very much $)$. These specific questions were included to examine how sociable participants perceived themselves in their daily life because previous research has shown those with a potential addiction can have socialization problems (e.g., Lin et al. 2015; Yang et al. 2010).

\section{Statistical Analysis}

The continuous data were calculated using means and standard deviations (SDs), while the categorical data were calculated as percentages. Asymmetry and kurtosis were calculated for each item score. Acceptable values for asymmetry/asymmetry and kurtosis are in the range from -1 to +1 in the case of normal univariate data distribution (Streiner and Norman 1995). A descriptive analysis of the scores obtained on the Italian SABAS was carried out, including gender, age, and level of education. The internal consistency of the overall score was calculated using Cronbach's alpha coefficient. Indicators of discriminative validity were determined by comparing the SABAS scores based on different socio-demographic variables. The convergent validity was investigated by using the validated Italian NMP-Q. The nomological validity (i.e., the construct validity comparing constructs with an expected association) was investigated via correlations between the questions posed to participants, the results of the SABAS, and the NMP-Q creating a validation network that reflected the construct investigated and those theoretically associated with it. In order to determine goodness of fit of the confirmatory factor analysis (CFA), Kaiser-Meyer-Olkin (KMO), root mean square residuals (RMSEA), standardized root mean square residuals (SRMR), Tucker-Lewis Index (TLI), comparative fit index (CFI), goodness of fit index (GFI), and adjusted goodness of fit index (AGFI) were all calculated. MacCallum et al. (1996) have used 0.01, 0.05, and 0.08 to indicate excellent, good, and mediocre fit, respectively. The analysis was carried out using the following statistical packages: FACTOR v. 10.10.01 (Ferrando and Lorenzo-Seva 2017), SPSS 
Statistics v.25 (IBM Corporation 2017) and "R" software (R Core Team 2014) with package lavaan (Rosseel 2012).

\section{Ethics}

All the procedures carried out in the present study were in accordance with the Helsinki declaration and with the approval of the research team's institutional research committee. All participants were assured that their data were anonymous and confidential and that they could withdraw their participation at any time.

\section{Results}

The socio-demographic characteristics of the participants showed that in relation to the educational level, $34.1 \%$ of respondents had a university degree and $58.6 \%$ have a high school degree. Over half of the participants $(59 \%)$ were in a romantic relationship. As for smartphone ownership, $70.1 \%$ of the participants owned one smartphone. Two-thirds of the sample reported being able to abstain from smartphone use for up to $24 \mathrm{~h}(63 \%)$, while remaining participants $(37 \%)$ stated not to be able to do so. Participants stated that they habitually used their smartphones for about $2.9 \mathrm{~h}$ per day $(\mathrm{SD}=3.13)$, either for work or study reasons. Twofifths of the sample had "very high" engagement in buying smartphone apps. The mean score on the SABAS was 15 (out of $36: \mathrm{SD}=6.68$ ).

\section{Validity Testing of the SABAS: Confirmatory Factor Analysis}

First, the descriptive statistics of the SABAS items were examined and are reported in Table 1. The results showed a general positive skewness and, consequently, a relatively low frequency of responding to the higher scores in the scale for all items. After the initial analysis confirmed the one-factor model (i.e., a single factor structure, eigenvalue $=4.16$, T-size comparative fit index $($ Ts-CFI $)=.988)$, confirming previous research (i.e., Csibi et al. 2018), a CFA was performed on the six items of SABAS.

Since there is no consensus on the indexes of adaptation for the evaluation of models (see Bollen and Long 1993; Boomsma 2000; Hoyle et al. 2002), the goodness of model fit was based on different indices. In this specific case, because the items were distributed in a normal way (between +1 and -1 on all items), the robust maximum likelihood (RML) method was

Table 1 Summary (CFA) and descriptive statistic of SABAS

\begin{tabular}{llllll}
\hline Item & Mean & CI (95\%) & Skewness & Kurtosis & $\lambda^{*}$ \\
\hline Item 1 & 2.019 & $(1.79,2.25)$ & 1.076 & -0.105 & .862 \\
Item 2 & 2.495 & $(2.24,2.75)$ & 0.424 & -1.197 & 724 \\
Item 3 & 2.024 & $(1.80,2.24)$ & 0.846 & -0.597 & 906 \\
Item 4 & 2.047 & $(1.81,2.28)$ & 1.018 & -0.300 & 869 \\
Item 5 & 2.297 & $(2.05,2.54)$ & 0.716 & -0.788 & 792 \\
Item 6 & 3.203 & $(2.97,3.43)$ & -0.006 & -1.021 & 556 \\
\hline
\end{tabular}

$C I=$ confidence interval

$* \lambda=$ factor loadings 
used (e.g., Calafiore and El Ghaoui 2001; Muthén and Kaplan 1985) alongside Pearson's correlations (see Table 2). The results obtained for the one-factor model provided an acceptable fit with $75.6 \%$ of the explained common variance (Fornell and Larcker 1981). The KMO was .898 , RMSR was .061, TLI was .998, AGFI was .997, RMSEA was .060, GFI was .994, and CFI was .996 ( $X^{2}[\mathrm{df}=9], p=.092$; the chi-square test is very sensitive to sample size, which is why other indexes of goodness were used [Brown 2015]). Notably, the CFI and the TLI were larger than .95 and the RMSEA was lower than .08 (i.e., Hu and Bentler 1999). These results support the factorial validity of the SABAS (i.e., Cerny and Kaiser 1977; Kaiser 1974) given that the indices obtained were acceptable and all factor loading was high (i.e., $\lambda \mathrm{ij} \geq .50$; Ferguson and Cox 1993).

\section{Reliability Analysis}

The reliability of the Italian version of SABAS was assessed using various indicators. Cronbach's alpha reliability coefficient was very good $(\alpha=.890)$ and could not be improved by deleting any item. The factor score determinacy coefficient of the SABAS was excellent (.929, above the desired threshold of .80 [Muthén and Muthén 2012]), as was the composite reliability coefficient (.900). Finally, the discriminating power was assessed using Pearson's correlations, and all six items were statistically significant and positively associated with the total score (Item $1=.677$; Item $2=.869 ;$ Item $3=.803 ;$ Item $4=.900 ;$ Item $5=.800 ;$ Item $6=.878$ ).

\section{Validity of the Construct: Nomological Validation, Convergence, and Criterion Validity}

The evaluation of the validity of the SABAS also involved the identification of a relevant network of associated key constructs and aimed to explain the interrelation models existing between them (Bryant et al. 2007). This procedure was developed and discussed by Cronbach and Meehl (1955), who argued that it was important to understand the nature of a construct through precise laws. More specifically they said that: "in a nomological network may relate (a) observable properties or quantities to each other; or (b) theoretical constructs to observabIes; or (c) different theoretical constructs to one another. These laws may be statistical or deterministic.” (p. 290).

A nomological network represents constructs as nodes, while every edge (connecting constructs) represents a relationship between constructs in a hypothesis (Cronbach 1987). Using Pearson's correlation coefficient, the total SABAS score was correlated with several variables related to smartphone use and behaviors. Convergent validity was determined by examining the correlation between total SABAS score and total score on the NMP-Q, which was highly significant $(r=.845)$. As they assess similar constructs, such a result suggests a

Table 2 Standardized variance/covariance matrix of SABAS items (Pearson's correlations)

\begin{tabular}{|c|c|c|c|c|c|c|}
\hline Item & 1 & 2 & 3 & 4 & 5 & 6 \\
\hline Item 1 & 1.000 & & & & & \\
\hline Item 2 & $0.591 * *$ & 1.000 & & & & \\
\hline Item 3 & $0.777 * *$ & $0.625 * *$ & 1.000 & & & \\
\hline Item 4 & $0.772 * *$ & $0.630 * *$ & $0.681 * *$ & 1.000 & & \\
\hline Item 5 & $0.695^{* *} *$ & $0.592 * *$ & $0.637 * *$ & $0.650 * *$ & 1.000 & \\
\hline Item 6 & $0.483^{* *}$ & $0.402 * *$ & $0.497 * *$ & $0.512 * *$ & $0.480 * *$ & 1.000 \\
\hline
\end{tabular}

**Statistically significant at $p<.001$ 
good convergent validity between the two scales. The additional variables explored in the present study resulted to be correlated with the total scores of the SABAS and the NMP-Q, indicating a possible connection to smartphone addiction.

In particular, positive correlations were found between the SABAS and the NMP-Q score and the frequency of daily use of smartphone applications $(r=.424)$; the degree of perceived importance of the smartphone in the participant's life $(r=.486)$; the perceived skillfulness in using the smartphone and its apps $(r=.294)$; the establishment of friendships or romantic relationships with people they knew online via chat, forums, social networks or video games $(r=.500)$; and frequent daily use of smartphone apps $(r=.461)$. Moreover, a positive correlation was found between the total SABAS score and the mean daily hours of smartphone use $(r=.210)$. Finally, the frequency of online shopping with smartphone apps was also correlated with the SABAS total score $(r=.300)$.

A negative correlation was found between the total SABAS scores and the NMP-Q and the questions related to perceived quality of life and sociability. Higher scores on the quality of life single-item measure and in-person socialization were inversely correlated with the total scores on the SABAS and the NMP-Q. More specifically, the quality of life satisfaction score was negatively correlated with the total SABAS score $(r=-.280)$ and with the total NMP-Q score $(r=-.200)$. Sociability was negatively correlated with the total SABAS score $(r=-.202)$ and with the total NMP-Q score $(r=-.240)$. Participants' age was negatively correlated with the total SABAS score $(r=-222)$.

\section{Discussion}

In the present study, the psychometric properties of the Italian version of the SABAS were tested and all three hypotheses were confirmed. The factorial analysis of the six SABAS items identified a unidimensional factor (i.e., a single construct component). Analyzing the psychometric characteristics of the SABAS, the analyses showed good internal reliability and consistency. Convergent validity was confirmed by its significant correlation with NMP-Q. The results agree with other validation studies of the scale related to smartphone addiction supporting a one-factor construct (e.g., Lee et al. 2018), along with good reliability and validity.

Furthermore, the findings in the present study tentatively confirmed that some variables are associated with potential online addiction, as assessed by both the SABAS and NMP-Q (Csibi et al. 2018; Lin et al. 2019; Yam et al. 2019). Total scores on both tests (i.e., SABAS and NMP-Q) were correlated with frequency of smartphone apps use, hours spent on the smartphone, frequency of online purchases with apps, and the extent of online socialization, while higher scores on the quality of life item and in-person socialization were inversely correlated with the total scores of both the SABAS and NMP-Q. These results suggest that the SABAS has good face validity and criterion validity.

This is in accordance with several studies, which have previously demonstrated the negative influence of smartphone addiction on everyday behavior (e.g., Panova and Carbonell 2018). For instance, it has been previously noted that smartphone addiction results in a higher probability of social isolation, while online socialization practices such as obsessively checking notifications or compulsively commenting and sharing friends' pictures increase, accompanied by lower levels of self-esteem and lower reported quality of life (e.g., Tangmunkongvorakul et al. 2019). 
Regarding sociability, a negative correlation was present, though not particularly strong. However, such a result is in accordance with previous studies (e.g., Enez Darcin et al. 2016), suggesting that smartphone addiction may lead to a lower willingness to socialize with people (Elhai et al. $2017 \mathrm{a}, \mathrm{b})$. The negative correlation with life satisfaction is also in accordance with findings from previous studies (e.g., Samaha and Hawi 2016). It has previously been hypothesized that increased smartphone and app use (e.g., social media) may be associated with the desire to temporarily step away from daily stress, personal suffering, and/or from depression symptoms (Enez Darcin et al. 2016; Verduyn et al. 2017). The present study also found that age was negatively correlated with the total SABAS score. Such a result suggests that as individuals get older, problematic smartphone use is less likely. This partially reflects the results of previous studies in which older people tend to use smartphones primarily as a source of information rather than for its social functions (e.g., Andone et al. 2016). Furthermore, with regard to the SABAS score, only three participants reached the maximum score obtainable (i.e., approximately $1 \%$ of the total sample). Therefore, the index for the maximum score is low and is in line with what has been defined by previous research (e.g., Billieux et al. 2015; Elhai et al. 2017b; Lopez-Fernandez 2017).

The present study is not without limitations. The study was conducted on a small sample of healthy volunteers, rather than on a large clinical sample, and the analyses were based on selfreport cross-sectional data from a small self-selected sample of participants and included some single-item measures (e.g., quality of life and sociability). Therefore, data were collected solely for exploratory purposes. Further investigation of Italian participants is needed in order to confirm the preliminary results provided by the present study using bigger and more representative samples and more robust (non-single-item) scales. Future studies should also investigate possible interactions between participants' education level and the total SABAS score. Such relationship was not investigated in the present study because of the homogeneity of the sample's educational levels. Similarly, the possible interaction between participants' gender and the total SABAS score should be further investigated in future studies because the sample size was too small in the present study to examine such effects.

Despite supporting the existence of possible addictive symptoms related to smartphone use, the results are not intended as a source of a diagnostic profile, and no information was provided regarding the long-term dangers and persistence of smartphone addiction. However, the psychometric testing of the Italian SABAS demonstrates that it assesses a unidimensional construct and that it is a reliable and valid tool for assessing the risk of addiction to smartphone applications among Italian adults.

\section{Compliance with Ethical Standards}

Conflict of Interest The authors declare that they have no conflict of interest.

Ethical Approval All the procedures carried out in the present study were in accordance with the Helsinki declaration and with the approval of the research team's institutional research committee. All participants were assured that their data were anonymous and confidential and that they could withdraw their participation at any time.

Informed Consent Informed consent was obtained from all participants.

Open Access This article is licensed under a Creative Commons Attribution 4.0 International License, which permits use, sharing, adaptation, distribution and reproduction in any medium or format, as long as you give appropriate credit to the original author(s) and the source, provide a link to the Creative Commons licence, and indicate if changes were made. The images or other third party material in this article are included in the article's 
Creative Commons licence, unless indicated otherwise in a credit line to the material. If material is not included in the article's Creative Commons licence and your intended use is not permitted by statutory regulation or exceeds the permitted use, you will need to obtain permission directly from the copyright holder. To view a copy of this licence, visit http://creativecommons.org/licenses/by/4.0/.

\section{References}

Adawi, M., Bragazzi, N. L., Argumosa-Villar, L., Boada-Grau, J., Vigil-Colet, A., Yildirim, C., et al. (2018). Translation and validation of the nomophobia questionnaire in the Italian language: Exploratory factor analysis. JMIR mHealth and uHealth, 6(1), e24. https://doi.org/10.2196/mhealth.9186 .

Andone, I., Błaszkiewicz, K., Eibes, M., Trendafilov, B., Montag, C., \& Markowetz, A. (2016). How age and gender affect smartphone usage. In: Proceedings of the 2016 ACM international joint conference on pervasive and ubiquitous computing (pp. 9-12). Heidelberg, Germany: ACM. https://doi.org/10.1145 /2968219.2971451.

Balakrishnan, J., \& Griffiths, M. D. (2018). An exploratory study of 'selfitis' and the development of the Selfitis Behavior Scale. International Journal of Mental Health and Addiction, 16, 722-736. https://doi.org/10.1007 /s11469-017-9844-x.

Banyai, F., Zsila, A., Kiraly, O., Maraz, A., Elekes, Z., Griffiths, M. D., et al. (2017). Problematic social media use: Results from a large-scale nationally representative adolescent sample. PLoS One, 12(1), e0169839. https://doi.org/10.1371/journal.pone.0169839.

Beaton, D. E., Bombardier, C., Guillemin, F., \& Ferraz, M. B. (2000). Guidelines for the process of cross-cultural adaptation of self-report measures. Spine, 25(24), 3186-3191. https://doi.org/10.1097/00007632200012150-00014.

Belyaev, I., Dean, A., Eger, H., Hubmann, G., Jandrisovits, R., Johansson, O., ... \& Moshammer, H. (2015). EUROPAEM EMF Guideline 2015 for the prevention, diagnosis and treatment of EMF-related health problems and illnesses. Reviews on Environmental Health, 30, 337-371. https://doi.org/10.1515/reveh2015-0033.

Billieux, J., Maurage, P., Lopez-Fernandez, O., Kuss, D. J., \& Griffiths, M. D. (2015). Can disordered mobile phone use be considered a behavioral addiction? An update on current evidence and a comprehensive model for future research. Current Addiction Reports, 2(2), 156-162. https://doi.org/10.1007/s40429-015-0054-y.

Billieux, J., Blaszczynski, A., Colder-Carras, M., Edman, J., Heeren, A., Kardefelt-Winther, D., ... \& Van Rooij, A. J. (2017). Behavioral addiction: Open definition development. Open Science Framework. https://oi. org/10.17605/OSF.IO/Q2VVA.

Bollen, K. A., \& Long, J. S. (1993). Testing structural equation models (Vol. 154). London: Sage.

Boomsma, A. (2000). Reporting analyses of covariance structures. Structural Equation Modeling, 7(3), 461-483. https://doi.org/10.1207/S15328007SEM0703 6.

Brown, T. A. (2015). Confirmatory factor analysis for applied research (2nd ed.). New York: Guilford Press.

Bryant, F. B., King, S. P., \& Smart, C. M. (2007). Multivariate statistical strategies for construct validation in positive psychology. In A. D. Ong \& M. H. M. van Dulmen (Eds.), Oxford handbook of methods in positive psychology (pp. 61-82). New York: Oxford University Press.

Calafiore, G., \& El Ghaoui, L. (2001). Robust maximum likelihood estimation in the linear model. Automatica, 37(4), 573-580. https://doi.org/10.1016/S0005-1098(00)00189-8.

Cerny, C. A., \& Kaiser, H. F. (1977). A study of a measure of sampling adequacy for factor-analytic correlation matrices. Multivariate Behavioral Research, 12(1), 43-47.

Chóliz, M. (2012). Mobile-phone addiction in adolescence: The test of mobile phone dependence (TMD). Progress in Health Sciences, 2(1), 33-44.

Chotpitayasunondh, V., \& Douglas, K. M. (2016). How "phubbing" becomes the norm: The antecedents and consequences of snubbing via smartphone. Computers in Human Behavior, 63, 9-18. https://doi.org/10.1016 j.chb.2016.05.018.

Chotpitayasunondh, V., \& Douglas, K. M. (2018). The effects of "phubbing" on social interaction. Journal of Applied Social Psychology, 48(6), 304-316. https://doi.org/10.1111/jasp.12506.

Comrey, A. L. (1988). Factor-analytic methods of scale development in personality and clinical psychology. Journal of Consulting and Clinical Psychology, 56(5), 754-761. https://doi.org/10.1037/0022-006 X.56.5.754.

Corazza, M., Minghetti, S., Bertoldi, A. M., Martina, E., Virgili, A., \& Borghi, A. (2016). Modern electronic devices: An increasingly common cause of skin disorders in consumers. Dermatitis, 27(3), 82-89. https://doi.org/10.1097/DER.0000000000000184. 
Cronbach, L. J. (1987). Statistical tests for moderator variables: Flaws in analyses recently proposed. Psychological Bulletin, 102(3), 414-417. https://doi.org/10.1037/0033-2909.102.3.414.

Cronbach, L. J., \& Meehl, P. E. (1955). Construct validity in psychological tests. Psychological Bulletin, 52(4), 281-302. https://doi.org/10.1037/h0040957.

Csibi, S., Demetrovics, Z., \& Szabo, A. (2016). Hungarian adaptation and psychometric characteristics of Brief Addiction to Smartphone Scale (BASS). Psychiatria Hungarica, 31(1), 71-77.

Csibi, S., Griffiths, M. D., Cook, B., Demetrovics, Z., \& Szabo, A. (2018). The psychometric properties of the Smartphone Applications-Based Addiction Scale (SABAS). International Journal of Mental Health and Addiction, 16, 393-403. https://doi.org/10.1007/s11469-017-9787-2.

David, P., Kim, J., Brickman, J. S., Ran, W., \& Curtis, C. M. (2015). Mobile phone distraction while studying. New Media \& Society, 17(10), 1661-1679. https://doi.org/10.1177/1461444814531692.

Demirci, K., Akgonul, M., \& Akpinar, A. (2015). Relationship of smartphone use severity with sleep quality, depression, and anxiety in university students. Journal of Behavioral Addictions, 4(2), 85-92. https://doi. org/10.1016/j.jad.2016.08.030.

Elhai, J. D., Levine, J. C., Dvorak, R. D., \& Hall, B. J. (2016). Fear of missing out, need for touch, anxiety and depression are related to problematic smartphone use. Computers in Human Behavior, 63, 509-516. https://doi.org/10.1016/j.chb.2016.05.079.

Elhai, J. D., Dvorak, R. D., Levine, J. C., \& Hall, B. J. (2017a). Problematic smartphone use: A conceptual overview and systematic review of relations with anxiety and depression psychopathology. Journal of Affective Disorders, 207, 251-259. https://doi.org/10.1016/j.jad.2016.08.030.

Elhai, J., Levine, J., Dvorak, R., \& Hall, B. (2017b). Non-social features of smartphone use are most related to depression, anxiety and problematic smartphone use. Computers in Human Behavior, 69, 75-82. https:/doi. org/10.1016/j.chb.2016.12.023.

Enez Darcin, A., Kose, S., Noyan, C. O., Nurmedov, S., Yılmaz, O., \& Dilbaz, N. (2016). Smartphone addiction and its relationship with social anxiety and loneliness. Behaviour \& Information Technology, 35(7), 520525. https://doi.org/10.1080/0144929X.2016.1158319.

Ezoe, S., Toda, M., Yoshimura, K., Naritomi, A., Den, R., \& Morimoto, K. (2009). Relationships of personality and lifestyle with mobile phone dependence among female nursing students. Social Behavior and Personality, 37(2), 231-238. https://doi.org/10.2224/sbp.2009.37.2.231.

Ferguson, E., \& Cox T. (1993). Exploratory factor analysis: a user's guide. International Journal of Selection and Assessment, 1(2), 84-94.

Ferrando, P. J., \& Lorenzo-Seva, U. (2017). Program FACTOR at 10: Origins, development and future directions. Psicothema, 29(2), 236-241. https://doi.org/10.7334/psicothema2016.304.

Fornell, C., \& Larcker, D. (1981). Evaluating structural equation models with unobservable variables and measurement error. Journal of Marketing Research, 18(1), 39-50. https://doi.org/10.2307/3151312.

Griffiths, M. D. (2005). A 'components' model of addiction within a biopsychosocial framework. Journal of Substance Use, 10, 191-197. https://doi.org/10.1080/14659890500114359.

Griffiths, M. D., \& Szabo, A. (2014). Is excessive online usage a function of medium or activity? An empirical pilot study. Journal of Behavioral Addictions, 3, 74-77. https://doi.org/10.1556/JBA.2.2013.016.

Guthold, R., Stevens, G. A., Riley, L. M., \& Bull, F. C. (2020). Global trends in insufficient physical activity among adolescents: A pooled analysis of 298 population-based surveys with $1 \cdot 6$ million participants. The Lancet Child \& Adolescent Health, 4(1), 23-35. https://doi.org/10.1016/S2352-4642(19)30323-2.

Heo, J. Y., Kim, K., Fava, M., Mischoulon, D., Papakostas, G. I., Kim, M. J., Kim, D. J., Chang, K. J., Oh, Y., Yu, B. H., \& Jeon, H. J. (2017). Effects of smartphone use with and without blue light at night in healthy adults: a randomized, double-blind, cross-over, placebo-controlled comparison. Journal of Psychiatric Research, 87, 61-70. https://doi.org/10.1016/j.jpsychires.2016.12.010.

Hoyle, R. H., Stephenson, M. T., Palmgreen, P., Lorch, E. P., \& Donohew, R. L. (2002). Reliability and validity of a brief measure of sensation seeking. Personality and Individual Differences, 32(3), 401-414. https://doi. org/10.1016/S0191-8869(01)00032-0.

Hu, L. T., \& Bentler, P. M. (1999). Cutoff criteria for fit indexes in covariance structure analysis: Conventional criteria versus new alternatives. Structural Equation Modeling, 6(1), 1-55. https://doi.org/10.1080 $/ 10705519909540118$.

IBM Corp (2017). IBM SPSS Statistics for Windows, Version 25.0. Armonk, NY: IBM Corp.

International Telecommunication Union (ITU). ITU committed to connecting the world: ICT facts and figures 2017 and global ICT developments. Retrieved September 21, 2019, from: https:/www.itu.int/en/ITUD/Statistics/Pages/stat/default.aspx.

Istituto Nazionale di Statistica/Automobile Club Italia. (2018). Incidenti Stradali Anno, 2017 Retrieved September 25, 2019, from: https:/www.istat.it/it/files/2018/07/Incidenti-stradali_2017.pdf.

Jeong, S., Kim, H., Yum, J., \& Hwang, Y. (2016). What type of content are smartphone users addicted to? SNS vs. games. Computers in Human Behavior, 54, 10-17. https://doi.org/10.1016/j.chb.2015.07.035. 
Jiang, Z., \& Zhao, X. (2016). Self-control and problematic mobile phone use in Chinese college students: The mediating role of mobile phone use patterns. BMC Psychiatry, 16, 416. https://doi.org/10.1186/s12888-0161131-z.

Kaiser, H. F. (1974). An index of factorial simplicity. Psychometrika, 39(1), 31-36. https://doi.org/10.1007 /BF02291575.

Kardefelt-Winther, D. (2014a). A conceptual and methodological critique of internet addiction research: Towards a model of compensatory internet use. Computers in Human Behavior, 31(1), 351-354. https://doi. org/10.1016/j.chb.2013.10.059.

Kardefelt-Winther, D. (2014b). Problematizing excessive online gaming and its psychological predictors. Computers in Human Behavior, 31(1), 118-122. https://doi.org/10.1016/j.chb.2013.10.017.

Kim, J., Hwang, Y., Kang, S., Kim, M., Kim, T. S., Kim, J., et al. (2016). Association between exposure to smartphones and ocular health in adolescents. Ophthalmic Epidemiology, 23(4), 269-276. https://doi. org/10.3109/09286586.2015.1136652.

Kuss, D., \& Griffiths, M. (2012). Online gaming addiction in children and adolescents: A review of empirical research. Journal of Behavioral Addictions, 1(1), 3-22. https://doi.org/10.1556/JBA.1.2012.1.1.

Kuss, D. J., \& Griffiths, M. D. (2017). Social networking sites and addiction: Ten lessons learned. International Journal of Environmental Research and Public Health, 14, 311. https://oi.org/10.3390/ijerph14030311 .

Kuss, D. J., Shorter, G. W., van Rooij, A. J., Griffiths, M. D., \& Schoenmakers, T. M. (2014). Assessing internet addiction using the parsimonious Internet addiction components model - A preliminary study. International Journal of Mental Health and Addiction, 12(3), 351-366. https://doi.org/10.1007/s11469-013-9459-9 .

Lee, S., Kim, M., Mendoza, J. S., \& McDonough, I. M. (2018). Addicted to cellphones: exploring the psychometric properties between the nomophobia questionnaire and obsessiveness in college students. Heliyon, 4(11), e00895. https://doi.org/10.1016/j.heliyon.2018.e00895.

Lepp, A., Barkley, J. E., \& Karpinski, A. C. (2015). The relationship between cell phone use and academic performance in a sample of U.S. college students. SAGE Open, 5(1), 1-9. https://doi.org/10.1177 $/ 2158244015573169$.

Lin, Y. H., Chang, L. R., Lee, Y. H., Tseng, H. W., Kuo, T. B. J., \& Chen, S. H. (2014). Development and validation of the Smartphone Addiction Inventory (SPAI). PLoS One, 9, e98312. https://doi.org/10.1371 /journal.pone.0098312.

Lin, T. T., Chiang, Y. H., \& Jiang, Q. (2015). Sociable people beware? Investigating smartphone versus nonsmartphone dependency symptoms among young Singaporeans. Social Behavior and Personality, 43(7), 1209-1216. https://doi.org/10.2224/sbp.2015.43.7.1209.

Lin, C.-L., Imani, V., Broström, A., Nilsen, P., Griffiths, M. D., \& Pakpour, A. H. (2019). Smartphone application-based addiction among Iranian adolescents: A psychometric study. International Journal of Mental Health and Addictions, 17, 765-780. https://doi.org/10.1007/s11469-018-0026-2 .

Long, J., Liu, T. Q., Liao, Y. H., Qi, C., He, H. Y., Chen, S. B., \& Billieux, J. (2016). Prevalence and correlates of problematic smartphone use in a large random sample of Chinese undergraduates. BMC Psychiatry, 16, 408. https://doi.org/10.1186/s12888-016-1083-3.

Lopez-Fernandez, O. (2015). How has internet addiction research evolved since the advent of internet gaming disorder? An overview of cyberaddictions from a psychological perspective. Current Addiction Reports, 2, 263-271. https://doi.org/10.1007/s40429-015-0067-6.

Lopez-Fernandez, O. (2017). Short version of the smartphone addiction scale adapted to Spanish and French: Towards a cross-cultural research in problematic mobile phone use. Addictive Behaviors, 64, 275-280. https://doi.org/10.1016/j.addbeh.2015.11.013 .

MacCallum, R. C., Browne, M. W., \& Sugawara, H. M. (1996). Power analysis and determination of sample size for covariance structure modeling. Psychological Methods, 1, 130-149. https://doi.org/10.1037/1082-989 X.1.2.130.

Martinotti, G., Villella, C., Di Thiene, D., Di Nicola, M., Bria, P., Conte, G., ... \& La Torre, G. (2011). Problematic mobile phone use in adolescence: A cross-sectional study. Journal of Public Health, 19(6), 545-551. https://doi.org/10.1007/s10389-011-0422-6 .

Muthén, B., \& Kaplan, D. (1985). A comparison of some methodologies for the factor analysis of non-normal Likert variables. British Journal of Mathematical and Statistical Psychology, 38(2), 171-189. https://oi. org/10.1111/j.2044-8317.1985.tb00832.x.

Muthén, L. K., \& Muthén, B. O. (2012). MPlus: statistical analysis with latent variables - user's guide. Los Angeles: Muthén \& Muthén.

Panova, T., \& Carbonell, X. (2018). Is smartphone addiction really an addiction? Journal of Behavioral Addictions, 7(2), 252-259. https://doi.org/10.1556/2006.7.2018.49.

Pontes, H. M., Szabo, A., \& Griffiths, M. D. (2015). The impact of Internet-based specific activities on the perceptions of internet addiction, quality of life, and excessive usage: A cross-sectional study. Addictive Behaviors Reports, 1, 19-25. https://doi.org/10.1016/j.abrep.2015.03.002 . 
R Core Team (2014). R: A language and environment for statistical computing. R Foundation for statistical computing. Vienna. Retrieved January 16, 2020, from: http://www.R-project.org/.

Rebold, M., Sheehan, T., Dirlam, M., Maldonado, T., \& O’Donnell, D. (2016). The impact of cell phone texting on the amount of time spent exercising at different intensities. Computers in Human Behavior, 55, 167-171. https://doi.org/10.1016/j.chb.2015.09.005.

Rice, E., Rhoades, H., Winetrobe, H., Sanchez, M., Montoya, J., Plant, A., \& Kordic, T. (2012). Sexually explicit cell phone messaging associated with sexual risk among adolescents. Pediatrics, 130(4), 667-673. https://doi.org/10.1542/peds.2012-0021.

Roberts, J. A., \& David, M. E. (2016). My life has become a major distraction from my cellphone: Partner phubbing and relationship satisfaction among romantic partners. Computers in Human Behavior, 54, 134 141. https://doi.org/10.1016/j.chb.2015.07.058.

Rosseel, Y. (2012). lavaan: An R package for structural equation modeling and more version 0.5-12 BETA. Journal of Statistical Software, 48(2), 1-36.

Salehan, M., \& Negahban, A. (2013). Social networking on smartphones: When mobile phones become addictive. Computers in Human Behavior, 29, 2632-2639. https://doi.org/10.1016/j.chb.2013.07.003.

Samaha, M., \& Hawi, N. S. (2016). Relationships among smartphone addiction, stress, academic performance, and satisfaction with life. Computers in Human Behavior, 57, 321-325. https://doi.org/10.1016/j. chb.2015.12.045.

Stevens, J., \& Egger, G. (2017). A review of small screen and internet technology-induced pathology as a lifestyle determinant of health and illness. American Journal of Lifestyle Medicine. https://doi.org/10.1177 /1559827617749171.

Streiner, D. L., \& Norman, G. R. (1995). Health measurement scales. A practical guide to their development and use (2nd ed.). Oxford: Oxford Medical Publications.

Tangmunkongvorakul, A., Musumari, P. M., Thongpibul, K., Srithanaviboonchai, K., Techasrivichien, T., Suguimoto, S. P., Ono-Kihara, M., \& Kihara, M. (2019). Association of excessive smartphone use with psychological well-being among university students in Chiang Mai, Thailand. PLoS One, 14(1), e0210294. https://doi.org/10.1371/journal.pone.0210294.

Taylor, K., Silver, L. (2019). Smartphone ownership is growing rapidly around the world, but not always equally. Pew Research Center, February 5. Retrieved September 25, 2019, from: https://www.pewresearch. org/global/2019/02/05/smartphone-ownership-is-growing-rapidly-around-the-world-but-not-alwaysequally/.

van der Schuur, W. A., Baumgartner, S. E., \& Sumter, S. R. (2019). Social media use, social media stress, and sleep: Examining cross-sectional and longitudinal relationships in adolescents. Health Communication, 34(5), 552-559. https://doi.org/10.1080/10410236.2017.1422101.

Verduyn, P., Ybarra, O., Résibois, M., Jonides, J., \& Kross, E. (2017). Do social network sites enhance or undermine subjective wellbeing? A critical review. Social Issues and Policy Review, 11(1), $274-302$. https://doi.org/10.1111/sipr.12033.

Widyanto, L., \& Griffiths, M. D. (2006). 'Internet addiction': A critical review. International Journal of Mental Health and Addiction, 4(1), 31-51. https://doi.org/10.1007/s11469-006-9009-9.

Yam, C-Y., Pakpour, A., Griffiths, M. D., Yau, W-Y., Lo, C-Y.M., ... Leung, H. (2019). Psychometric testing of three Chinese online-related addictive behavior instruments among Hong Kong university students. Psychiatric Quarterly, 90, 117-128. https://doi.org/10.1007/s11126-018-9610-7.

Yang, Y., Yen, J., Ko, C., Cheng, C., \& Yen, C. (2010). The association between problematic cellular phone use and risky behaviors and low self-esteem among Taiwanese adolescents. BMC Public Health, 10, 217. https://doi.org/10.1186/1471-2458-10-217.

Yildirim, C., \& Correia, A. P. (2015). Exploring the dimensions of nomophobia: development and validation of a self-reported questionnaire. Computers in Human Behavior, 49, 130-137. https://doi.org/10.1016/j. chb.2015.02.059.

Publisher's Note Springer Nature remains neutral with regard to jurisdictional claims in published maps and institutional affiliations. 